\title{
Determining Power Transformer Core Dimension Under Nonlinear Load Operation
}

\author{
Syafrudin Masri, Muhammad Mokhzaini Azizan, and Mohamad Kamarol Mohd Jamil
}

\begin{abstract}
Determination of power transformer dimension associated with theoretical calculation and manufacturers' testing procedures. Built for various users, the transformers are calibrated strictly using standards such as ANSI/IEEE C57.110 and IEEE C.57.12.01 1989. However, none of the calibration and testing considered harmonic situations in depth. Problems of harmonics are unique and rise exponentially since the 1970s. The RMS value of current is higher under harmonics condition, and the calibration and testing of power transformer is no longer applied because the current becomes nonlinear. The additional losses in steel cores, and windings translated into higher operational temperatures could lead the transformers to permanent malfunction through several causes like core saturation and explosion of windings. This paper examines the inclusion of harmonic current in determining core dimension of a three phase power transformer. The differences of Area Product, power rating, and apparent power in transformer operating with sinusoidal and harmonic current are mentioned. In the end, this paper provides sufficient mathematical explanation in justifying the need to alter the dimension of a power transformer to work in harmonics surrounding.
\end{abstract}

Index Terms - Core, Currents, Harmonics, Nonlinear loads, Power transformers

\section{INTRODUCTION}

The numbers of electronic devices exist today are easily exponentially more than they were in 1970s or 1980s. The preference of these loads, which also known as nonlinear loads, is due to their automatic mechanism ability and absolute precision. While manual labour need rests and welfares, these nonlinear loads keep working on, accurately following the settings been set upon them. Despite their ample abilities, worrying power quality issues exist due to the loads existence. The electronic devices inside the loads tend to inflict massive changes to the current and voltage initial sinusoidal state, making them no longer sinus [1],[3],[4] [8]. This is due to the continuous switching activities at rectification phase. These nonlinear loads, despite being fed by linear voltage, draw nonlinear current and their numbers

Manuscript received May 16, 2011; revised October 10, 2011. This research is made possible with the research and development allocation under Fundamental Research Grant Scheme made available by MOSTI and USM (FRGS 203/PELECT/6071144).

Syafrudin Masri is an Associate Profesor and a senior lecturer at the School of Electrical and Electronics Engineering, Universiti Sains Malaysia Engineering Campus, 14300 Nibong Tebal, Penang, Malaysia (e-mail: syaf@eng.usm.my).

Muhammad Mokhzaini Azizan is a Ph.D candidate at School of Electrical and Electronic Engineering, Universiti Sains Malaysia Engineering Campus, 14300 Nibong Tebal, Penang, Malaysia (e-mail: mokhzainiazizan@yahoo. com.my).

Mohamad Kamarol Mohd Jamil is with the Electrical Engineering Department, Universiti Sains Malaysia Engineering Campus, 14300 Nibong Tebal, Penang, Malaysia (e-mail: eekamarol@eng.usm.my). in power distribution system is continually grown rapidly. These currents are now consisting of fundamental components as well as harmonics components of higher order. Power transformers that sit between generation side (sinusoidal voltage source with $\pm 5 \%$ variation) and consumer's side (various nonlinear loads at each phase) are the ones that suffer due to harmonics. The main consequence is that they are now experiencing increase of losses particularly in the windings due to the deformed leakage field. Higher loss translated into higher operating temperature and deterioration of insulations and consequent short life span should they continue to work at the same level of which they certainly are.

In finding the perfect solution on this problem, the design of power transformer needs a massive reformation. Current practice by many manufacturers is that calibration and testing procedures conducted on production power transformers only involves sinusoidal current and voltages. In order to accommodate the extra losses that may experienced by the transformers, they allocate some operating margins. For example, most dry type transformers manufactures simply add $30^{\circ} \mathrm{C}$ to the average temperature rise, of which they obtain through empirical calculation [2],[7] [9]. The reformed part includes the parameters such as size, shape, and material of the core, as mentioned by Dsagupta [3]. Now that nonlinear current comes into consideration, the area product calculation needs to include the frequency of the harmonic currents, as well as magnitude of each of the current's harmonic components. This paper highlights the differences in term of Area Product, power rating, and apparent power as the loading of transformer changes from linear to nonlinear load. For comparison, the usually dominant order of $3^{\text {rd }}, 5^{\text {th }}$, and $7^{\text {th }}$ harmonics are considered, although in reality there is much more elements of harmonics in current.

\section{Selection of Core : MAterial, Shape AND Size}

The main parameters in selecting core for power transformer are material, shape, and size. The frequency of the transformer to be operating is important in order for its material to be determined. This is due to the materials indifference in resistivity, which in turn would influence eddy current existence and behaviour [5]. For example, power ferrites are a material with high resistivity which would be causing minimal amount of eddy current loss. However, they are of low permeability which would promote higher magnetizing current and for this snubbers and clamps might be needed. With metal alloy cores, the higher frequency materials have higher resistivity, thus lamination needed could be very slim. Abiding with these properties, 
ferrites have been the best material for power transformer application although its metal ruggedness might cause some problem in the end.

The shape of the core is important in order for the window to be allocated. The window would then define the winding breadth, number of layers, and the height of the core. The widest of window spaces means thicker winding breadth which in turn means minimal layers of windings. Minimal layer of windings means reduced ac resistance $\left(R_{a c}\right)$ and leakage inductance. Logically, wider windows also mean there is no need of the windings to be layered in height, of which they would be distributed in even. There are a lot of core shapes, namely PQ, pot, E-E, toroidal, and planar. Their properties vary in accordance to the frequency of operation, easiness of windings, and propagation of EMI. Pot and PQ cores are of small, almost square windows and have better magnetic shielding, of which greatly reduce EMI propagation. E-E core shapes include EC, ETD, and LP of which they possess great width of windows and used in low budget high efficiency power transformers. Toroidal core is great because of the lowest possible leakage inductance and very minimal number of layers, provided the windings are distributed evenly at entire core. It also has no end of layers, which means no creep age allowance, as well as no EMI propagation and no stray magnetic flux. However the downside is that by using toroidal shape core, automatic winding is impossible and the winding process is very difficult. Planar shapes are beginning to be used in SMPS, however they produced unique problems. The calculations are also more difficult due to the fact that changes of flux density and field intensity are great.

One widely method used in determining core's size is by referring to the core Area Product. It can be obtained by multiplying the core cross sectional area by the window area available for the winding [6]. However, there are many parameters involved in defining appropriate size of core, among them are power transformer's output power $\left(\mathrm{P}_{\mathrm{o}}\right)$, peak flux density $(\Delta \mathrm{B})$, transformer's operating frequency, and a constant for the type of power transformer. Core volume or area product does not necessarily translate into its power handling capability. Larger transformer needs to operate at lower power density due to heat dissipating surfacing area increases less than heat producing volume. Thermal properties of power transformer are usually hard to be accurately evaluated, be it by natural convection or forced air The following formula is used to produce the core Area Product, despite manufacturers prefers to modify and create their own in designing power transformers for various use.

$$
A P=A_{W} \cdot A_{E}\left(\frac{P_{o}}{K \Delta B f}\right)^{3 / 4} \mathrm{~cm}^{4}
$$

where $A_{w}=$ window area needed, $A_{E}=$ effective area, $P_{o}=$ power output, $\mathrm{K}=$ design coefficient, and $\mathrm{f}=$ operating frequency

This formula is based on several assumptions that are current density is $420 \mathrm{~A} / \mathrm{cm}^{2}$ in the windings and window utilization of $40 \%$ copper. Of course these are estimations; nonetheless the formula helps tremendously compared to try-and-error methods.

\section{Designing Power Transformer CORE : SinUSOIDAL CURRENT AND HARMONIC CURRENT}

In general there are a few factors to be taken into consideration when designing a power transformer, such as economic factor and efficiency, and both of them adhere to the need of using the best available materials. Selection of size, shape, material of the core, and number of primary and secondary turns are several technical matters need to be resolved. In this part, this paper explains the normal procedures of calculation in determining the size of the core, at first using fundamental/sinusoidal current parameter. The first of many steps is to define the specification of power transformer to be built. Table I shows parameters that usually being undertaken into consideration while building a transformer.

\begin{tabular}{lc}
\multicolumn{2}{c}{ TABLE I: SPECIFICATION OF POWER TRANSFORMER } \\
\hline \multicolumn{1}{c}{ Specification of 75VA Three Phase Power Transformer } \\
\hline Input primary voltage Vp & $240 \mathrm{~V}$ \\
Required secondary voltage Vs & $24 \mathrm{~V}$ \\
Required secondary current Is & $1.8 \mathrm{~A}$ \\
Winding configuration & Delta/Wye \\
Operating frequency of transformer & $50 \mathrm{~Hz}$ \\
Required transformer efficiency & $95 \%$ \\
Winding utilization factor & 0.4 \\
Preferred core material & E-I Laminated Silicon Steel \\
\hline \hline
\end{tabular}

In determining the size of the core, there are a few calculation involving the power rating, apparent transformer power, and Area Product (AP). This paper considers the above information in executing the calculations.

$$
\begin{aligned}
P(V A) & =\sqrt{3} \cdot V_{S} \cdot I_{S} \\
& =\sqrt{3}(24)(1.8)=75 \mathrm{VA}
\end{aligned}
$$

Since that is in three phase, thus for power rating per phase is $75 / 3=25 \mathrm{VA}$. Now consider the apparent power per phase of the transformer.

$$
\begin{aligned}
P_{T} & =P_{i}+P_{o}=\frac{P_{o}}{\eta}+P_{o}=\left(1+\frac{1}{\eta}\right) \cdot P_{o} \\
& =\left(1+\frac{1}{0.95}\right) \cdot 25 \mathrm{VA} \text { perphase }=51.25 \mathrm{~W}
\end{aligned}
$$

where $\mathrm{P}_{\mathrm{i}}=$ input power, and $\mathrm{P}_{\mathrm{o}}=$ output power

The Area Product can now be calculated using E-I core type properties, namely constant $\mathrm{K}_{\mathrm{j}}$ of 366 and exponential value $\mathrm{x}=-0.12$. It is based on the requirement that the transformer to be operated at $25^{\circ} \mathrm{C}$. By applying a much elaborated (1), the Area Product for designated transformer is now can be calculated.

$$
\begin{aligned}
A P & =\left[\frac{P_{T} \cdot 10^{4}}{K_{T} \cdot f \cdot B_{m} \cdot K_{u} \cdot K_{j}}\right]^{\frac{1}{1-x}} \\
& =\left[\frac{51.25 \cdot 10^{4}}{4.44 \cdot 50 \cdot 1.4 \cdot 0.4 \cdot 366}\right]^{\frac{1}{1+0.12}}=8.6 \mathrm{~cm}^{4}
\end{aligned}
$$

where $\mathrm{K}_{\mathrm{t}}=$ design coefficient, $\mathrm{f}=$ operating frequency, $\mathrm{B}_{\mathrm{m}}=$ maximum flux density, $\mathrm{K}_{\mathrm{u}}=$ window utilization factor, and $\mathrm{K}_{\mathrm{j}}=$ core configuration constant

The obtained $8.6 \mathrm{~cm}^{4}$ Area Product is produced by only taking fundamental current value into consideration. In the event of harmonic current, results by (2) and (3) no longer valid. If the design considers fundamental value of current 
and only $3^{\text {rd }}$ harmonic, thus the resultant Area of Product also is changed.

$$
\text { Power }(V A)=\sqrt{3} \cdot V_{S} \cdot I_{S}
$$

where $I_{s}$ equals to combination of fundamental and $3^{\text {rd }}$ harmonic current, $\quad \sum I=I_{1}+\frac{I_{1}}{n}$ with $\mathrm{n}=$ the number of harmonic orders. This paper takes the approach of identifying harmonic current through theoretical means due to its calculation easiness factor. The ever present harmonics are of $3^{\text {rd }}, 5^{\text {th }}, 7^{\text {th }}, 9^{\text {th }}$, and $11^{\text {th }}$, thus the total current flowing into the system can be calculated as below.

$$
\begin{aligned}
\sum I & =I_{1}+\frac{I_{1}}{n} \\
& =I_{1}+\frac{I_{1}}{3}+\frac{I_{1}}{5}+\cdots \frac{I_{1}}{11}=1.87 I_{1}
\end{aligned}
$$

The total current into the core is $\sum I=1.87 I_{1}$ where the resultant power rating of transformer that takes the usual dominant harmonic is amounted as follows.

$$
\text { Power }(V A)=\sqrt{3}(24)(1.87)(1.8)=139.9 V A
$$

In order to determine perphase power rating, thus $139.9 / 3$ $=46.6 \mathrm{VA}$. Now consider the apparent power per phase of the transformer.

$$
\begin{aligned}
P_{T} & =P_{i}+P_{o}=\frac{P_{o}}{\eta}+P_{o}=\left(1+\frac{1}{\eta}\right) \cdot P_{o} \\
& =\left(1+\frac{1}{0.95}\right) \cdot 46.6 \mathrm{VA} \text { perphase }=95.6 \mathrm{~W}
\end{aligned}
$$

The supposedly Area of Product can be calculated by substituting $\mathrm{P}_{\mathrm{T}}=95.6 \mathrm{~W}$ into (4), thus $\mathrm{AP}=16.04 \mathrm{~cm}^{4}$. Table II shows the differences in term of power rating and Area Product of transformer if it is to operate at sinusoidal current and harmonic current.

TABLE II: DIFFERENCES IN LOADING SINUS CURRENT AND SINUS AND $3{ }^{\text {RD }}$ HARMONIC CURRENT

\begin{tabular}{ccc}
\hline \hline Sinusoidal Current & Parameters & Harmonic Current \\
\hline 75 & Power rating (VA) & 139.9 \\
51.3 & $\begin{array}{c}\text { Apparent Power } \\
\text { PerPhase (W) }\end{array}$ & 95.6 \\
8.6 & Area Product $\left(\mathrm{cm}^{4}\right)$ & 16.04 \\
\# E-I 750 & $\begin{array}{c}\text { Appropriate selection } \\
\text { of core part }\end{array}$ & \# E-I 875 \\
\hline \hline
\end{tabular}

Since the desired core shape is E-I, thus in order to select appropriate core size to match values in Table II, a reference to Standard E-I Silicon Lamination Steel is made. The value that matches closest to the Area Product is selected. Thus for AP for transformer that operates with only sinus current, the nearest core is part \# E-I 750. As for the one operates with usually dominant harmonics of $3^{\text {rd }}, 5^{\text {th }}, 7^{\text {th }}, 9^{\text {th }}$, and $11^{\text {th }}$ nearest core is part \# E-I 875.

\section{Discussion}

The core sizing is made using AP approach where it is designed for easiness. Manufacturers' numeric codes are used to identify the cores part where information such as core dimensions and electrical properties are readily available. In order to differentiate the sizes and parts of the core for transformer operation under both sinusoidal current and no sinusoidal current, a few orders of harmonic are utilized. Although in real harmonic situation there are lot more harmonics component in current, this paper realized that it is sufficient to include just the selected orders of harmonics to show the difference in size and parts. The power rating of power transformer operating under sinusoidal current is lower than the one that operates under harmonic current. This is visible through the calculation of power rating where in sinusoidal state; the transformer is fed with only the fundamental component of current. Additional component in current has increased the power rating of power transformer by $86.5 \%$ more than it is when operating only with sinusoidal current.

Harmonic has increased the RMS value of current, resulting in additional requirement of power. Apparent power also has bumped by $86.5 \%$ and that actually consequence as the increase of power rating. It must be said that the increase of power rating and apparent power is not the increase of power ability, but it is more of the loss the transformer experienced. Simply put it this way, for the transformer with harmonics loading to operate the same ability as it is only with linear loads, it needs to increase its power rating to a bigger value $(86.5 \%$ compare to initial loss).

The difference in Area Product is the greatest testament in respect to power transformer operation with and without harmonics. With fundamental current, the Area Product necessitate small electric/ thermal/ and dimension E-I silicon cores. The part \# EI750 is of $11.2 \mathrm{~cm}$ (MLT), $11.4 \mathrm{~cm}$ (MPL), $\mathrm{Wa} / \mathrm{Ac} 0.790,3.448 \mathrm{~cm}^{2} \mathrm{~A}_{\mathrm{c}}, \mathrm{K}_{\mathrm{g}} 1.1253 \mathrm{~cm}^{5}$, and $\mathrm{A}_{\mathrm{t}} 120.0 \mathrm{~cm}^{2}$. The sizes of windows are also smaller of $8 \mathrm{~mm}$ each. As for bigger transformer with part \#EI-875, for example, the windows are at $11 \mathrm{~mm}, 13.0 \mathrm{~cm}$ (MLT), 13.3 (MPL). Wa/Ac $0.789, \mathrm{~A}_{\mathrm{c}} 4.693 \mathrm{~cm}^{2}, \mathrm{~K}_{\mathrm{g}} 2.513 \mathrm{~cm}^{5}$, and $\mathrm{A}_{\mathrm{t}} 163.0 \mathrm{~cm}^{2}$. The only logical explanation is the bigger core size means it can accommodate bigger amount of power rating. It is thus necessary for the size to increase in order for it to accommodate additional component in current, and for this case, it is the additional of harmonics in the current.

\section{CONCLUSION}

Two different designs of power transformer core are shown through calculation. The $A_{p}$ design approach is undertaken in order to fully utilise manufacturer's numeric codes that identifies the cores. For sinusoidal current, the Area Product of the designated power transformer is lower than of the one that operates with harmonic currents. The lower Area Product transformer size is smaller than the bigger Area Product transformer size, thus justifying the need of bigger core for harmonic currents situation.

\section{ACKNOWLEDGEMENT}

This research wishes to thank the workforce within the Power System Research Group and the Department of Electrical Engineering USM, mainly to the people at the Power Laboratory for their efforts and supports. 


\section{REFERENCES}

[1] M.D. Hwang, W.M. Grady, and H.W. Sanders, Jr. "Calculation of Winding Temperatures in Distribution Transformers Subjected to Harmonic Current," IEEE Trans. on Power Delivery, Vol. 3 (3). 1074-1079, 1988

[2] S.P. Kenedy, and C.L. Ivey. "Application, Design, and Rating of Transformer Containing Harmonic Currents," presented at the Pulp and Paper Industry Technical Conference. 19-31. 1990

[3] I. Dasgupta, Design of Transformers, New Delhi: Tata McGraw-Hill Publishing Company Limited.

[4] J. Desmet, and L. Lemko. Harmonics: Selection and Rating of Transformers. Power Quality Application Guide. Copper Development Association. 2005

[5] A. R. Abdul Razak, S. Taib, and I. Daut. "Design and Development of High Frequency Power Transformer for Renewable Energy Application," presented at the ROVISP 2005. Penang. 375-379, 2005

[6] N. Ekekwe, J.E. Ndubah, K. White, and O. Ben. "Practical Process in High Frequency Distribution Transformer Design," presented at the Proceedings of the Electrical Insulation Conference and Electrical Manufacturing \& Coil Winding Technology Conference. 121-128, 2003

[7] IEEE Recommended Practices and Requirements for Harmonic Control in Electrical Power Systems. IEEE Std 519-1992. IEEE Industry Applications Society/Power Engineering Society

[8] C. Venkatesh, D. Srikanth Kumar, D.V.S.S. Siva Sarma, and M. Sydulu. "Modelling of Nonlinear Loads and Estimation of Harmonics in Industrial Distribution System," presented at the $15^{\text {th }}$ National Power System Conference (NPSC), IIT Bombay. 592-597, 2008

[9] L.W. Pierce. "Transformer Design and Application Considerations for Nonsinusoidal Load Currents," IEEE Trans. On. Industry Applications. Vol. 32 (3). Pp. 633-645,1996

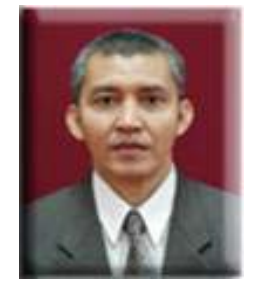

Syafrudin Masri was born in Pontianak, Indonesia in 1959. He received his B.Sc (Hons) degree in Electrical, M.Sc in Electric Energy Conversion, and $\mathrm{PhD}$ in Electrical Power from Bandung's Institute of Technology in 1987, 1992, and 2000 respectively.

His experiences in the field includes as Consultant for Mitsui. Co beginning 1987 until 1990 and for Daya Viotca from 1993-1997. Prior to joining USM in year 2000, he lectured at Tanjungpura University, Indonesia. His research interest includes Power Quality, Power Electronics Applications, Green and Renewable Technology, and others. He recently been awarded Associate Professorship as recognition of his work by USM.

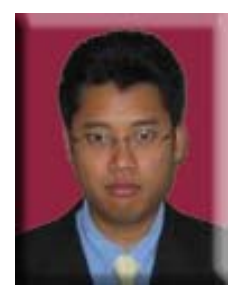

Muhammad Mokhzaini Azizan was born in Guar Chempedak, Kedah, Malaysia in 1983. He obtained his B.Sc from Universiti Teknikal Malaysia (UTeM) in year 2006, his M.Sc from Universiti Sains Malaysia (USM) in year 2009. Currently he is completing for his doctorate degree in USM.

His experiences in electrical and electronics field include apprenticeship at Pernec Corporation Bhd in year 2005 and as Research Officer for USM's Hajj Cluster Research Project from year 2008-2009. His research includes Power System Efficiency, Power Quality, and Green and Renewable Energy.

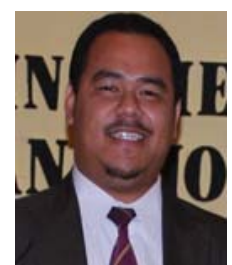

Mohamad Kamarol Mohd Jamil obtained his B.Eng from Universiti Teknologi Mara (UiTM) in year 2000, and both his M.Eng and D.Eng from Kyushu Institute of Technology, Japan in year 2005 and 2008 respectively.

His working stints include as engineer and senior engineer at Sankyo Seiki (M) Sdn. Bhd. Beginning $1994-2002$. Prior to joining USM in 2008, he worked as Research Assistant at High Voltage Laboratory at Kyushu Institute of Technology, Japan. He specialized in Partial Discharge Measurement and currently working in studying Palm Oil as liquid insulating material 